\title{
The Effect of Curing Time on the Engineering Properties of Sawdust and Lime Stabilized Expansive Soils
}

\author{
John Bosco Niyomukiza \\ Department of Civil Engineering \\ Diponegoro University \\ Semarang, Indonesia \\ niyojayb1992@student.undip.ac.id
}

\author{
Sri Prabandiyani Retno Wardani \\ Department of Civil Engineering \\ Diponegoro University \\ Semarang, Indonesia \\ wardani_spr@yahoo.com
}

\author{
Bagus Hario Setiadji \\ Department of Civil Engineering \\ Diponegoro University \\ Semarang, Indonesia \\ bhsetiadji@gmail.com
}

\begin{abstract}
Subgrade strength is the main factor in determining the required thickness of any pavement. Therefore, the properties of a pavement subgrade materials must be determined, as they can predict the service life of a pavement. This paper examines the deviation of strength attained by sawdust and lime stabilized expansive soils for subgrade during different curing periods. The methodology used was conducting laboratory tests such as physical properties and mechanical property tests for both treated and untreated soil samples. In the first set-up, the soil was substituted with sawdust in the percentages of $0,3,5$, and $7 \%$ of the dry weight of the soil, and after conducting unconfined compressive strength test, the optimum sawdust percentage obtained was $3 \%$. The $3 \%$ sawdust was then mixed with $3 \%$ lime and $94 \%$ soil for long term tests. The sawdust-lime stabilized samples were cured for $0,7,14$, and 28 days, and tested for unconfined compressive test and California Bearing Ratio. Based on the analysis of the results, it was concluded that a combination of $3 \%$ sawdust and $3 \%$ lime significantly improved the California Bearing Ratio and unconfined shear strength, specifically at later curing periods.
\end{abstract}

Keywords: lime, sawdust, curing time, UCS, CBR

\section{INTRODUCTION}

Pavement subgrade mainly consists of locally available soils, of which some of them are weak to support the upper layers of the pavement hence a major cause of pavement failures. These soils fail to support long-term pavement leading to pavement deterioration in terms of the development of cracks and potholes [1]. According to Fwa [2], the performance of any pavement depends upon the quality of the subgrade. A stabilized subgrade soil can provide a stronger pavement whereas a subgrade with poor engineering properties can result in inadequate pavement support, hence leading to a reduction in the design life of the pavement [3]. For that matter, the subgrade engineering properties need special attention because they influence the ability of the subgrade to resist force from the upper layers. If the load-bearing capacity of the subgrade is improved by any suitable means, then a lower thickness of road structure is needed, and eventually, road construction would be economical.

The subgrade soils with poor engineering properties include expansive clay soils. These soils possess threats to the construction of the pavement due to their low shear strength and high swelling characteristic [4]. In many cases, expansive soils have a high free swell index, and high plasticity index. According to Head [5], soils with free swell index less than $50 \%$ are less likely to show expansion properties, while the ones with swell index greater than $100 \%$ are susceptible to swelling under wet conditions. A plasticity index greater than $35 \%$ signifies that soil has high swelling potential [6]. According to Burmister [7], highly plastic soils begin with a plasticity index of 40 . To overcome the problem of swelling and shrinking, the expansive soils are either compacted or stabilized by chemicals or other stabilizers like wastes. Considering the trees that are cut across the globe, large quantities of sawdust are being generated [8-9]. Stabilizers increase workability, reduce the plasticity index and increase the strength of the soil [10, 11,12,13]. According to Khan \& Khan [14], about 10-13\% of the total volume of the wood $\log$ is processed into sawdust. Sawdust possesses little cementitious properties, but when blended with other materials having cementitious properties such as lime, their usage can yield better results $[8,14,15]$. According to Horisawa [16], dry wood consists of cellulose, lignin, hemicelluloses, and small amounts (5-10\%) of other materials. These components possess some cementitious properties. In the current study, the assessment of the strength of subgrade stabilized with sawdust and lime was carried out. These materials were added at $6 \%(3 \%$ lime $+3 \%$ sawdust) of dry soil weight. Both the treated and non-treated samples were cured for $0,7,14$, and 28 days in order to study the effect of curing time on engineering properties. Unconfined compressive strength and CBR were conducted at all curing times to investigate the engineering properties of soil-sawdust-lime mixtures.

\section{MATERIALS}

\section{A. Expansive Soil}

The expansive soil used in this study was from Godong sub-district, Grobogan District, Central Java Province, Indonesia, along Semarang-Purwodadi road at STA $49 \mathrm{Km}$. Both disturbed and undisturbed sampling techniques were used while collecting the samples. Before usage, the soil samples were oven-dried at a temperature of $600^{\circ} \mathrm{C}$. 


\section{B. Lime}

The lime used in this study is calcium oxide $(\mathrm{CaO})$, commonly known as quick lime. It was bought from the nearest hardware shop and then sieved through sieve No.40. Lime is prepared by burning limestone or calcium carbonate $\left(\mathrm{CaCO}_{3}\right)$ at elevated temperatures (between $850^{\circ} \mathrm{C}$ and $1200^{\circ} \mathrm{C}$ ) driving away carbon dioxide, thus forming calcium oxide as shown in (1).

$$
\text { Burning } \mathrm{CaCO}_{3}(\mathrm{~s})+\text { Heat } \rightarrow \mathrm{CaO}(\mathrm{s})+\mathrm{CO}_{2}(\mathrm{~g})
$$

\section{Sawdust}

Sawdust is a by-product that comes after cutting or pulverizing wood using a saw or any other blade in sawmill or lumbering industries. The sawdust used in the current study was acquired from the Woodwork Department, Politeknik Negeri Semarang (POLINES), Tembalang. Afterward, it was air-dried in an oven at a temperature of $600^{\circ} \mathrm{C}$, and then a selected sample was taken to the integrated laboratory, Universitas Diponegoro to determine the chemical composition of the sawdust sample. The sawdust used in this study was passed through sieve No.40 $(0.841 \mathrm{~mm})$. According to the concept of stabilization, some of the total weight of the sawdust whose diameter is smaller than the soil diameter works as fillers, thus filling the void between each successive particles, and the sawdust particles with bigger diameter than that of the soil covers the particles, thus increasing the bond (see Fig. 1). The chemical components of sawdust were analyzed by Energy Dispersive X-ray (EDX) and found out that the major chemical constituents were carbon $(61.9 \%)$, oxygen $(37.6 \%)$, and small percentages of other compounds. The previous studies by Singh et al. [17], and Phonphuak \& Chindaprasirt [18] also presents high carbon and oxygen contents in Sawdust (45\% and $30 \%$ respectively), and $(60.8 \%$ and $33.8 \%$ ), respectively. The carbon units are linked together by molecular bond, a strong bond that helps in sustaining part of stresses generated as a result of shed loads on the soil.

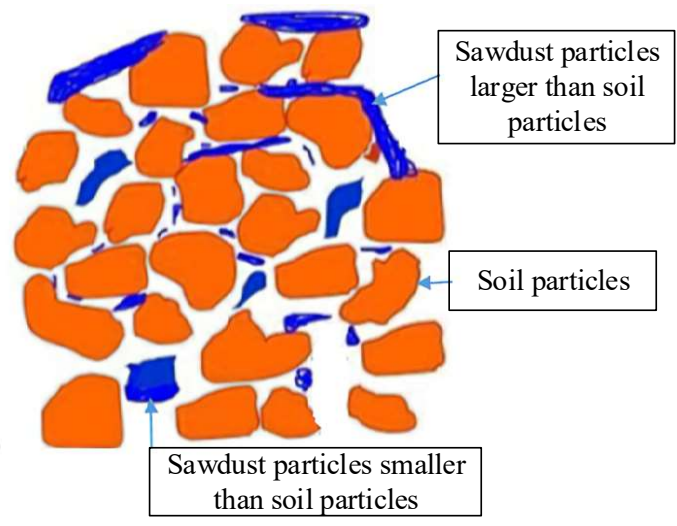

Fig. 1. Mechanism of sawdust to work as a soil filler material.

\section{METHODS}

All laboratory works were conducted in accordance to American Society for Testing and Materials (ASTM) standard procedures, as shown in TABLE I [19]. The soil samples were crushed using a rubber mallet into small sizes usually less than $4.75 \mathrm{~mm}$ sieve for compaction, CBR, and UCS tests, and less than $0.425 \mathrm{~mm}$ for Atterberg limit tests.

The tests conducted include; moisture content, Specific gravity to be used in the calculation of mass-volume relationship, Consistency limit (Atterberg limits), Free swell index (FSI) to measure the increase in volume of the soil with respect to the original volume, Grain-size distribution in order to group the particles into separate ranges of sizes, compaction test to obtain the optimum moisture content (OMC) and maximum dry density (MDD), CBR to determine the bearing capacity of the soil, and UCS to determine the unconfined shear strength of the soil. The CBR test was carried done in accordance to ASTM D-1883 procedures [20].

TABLE I. LABORATORY TESTS DESIGNATIONS [19]

\begin{tabular}{|l|l|}
\hline \multicolumn{1}{|c|}{ Test } & \multicolumn{1}{c|}{ Designation } \\
\hline Moisture content & D-2216 \\
\hline Specific gravity & D-854 \\
\hline Consistency limits & D-4318 \\
\hline Hydrometer Analysis & D-422 \\
\hline Sieve Analysis & D-421 \\
\hline Standard Proctor's Test & D-698 \\
\hline Unconfined Compressive Strength Test & D-2166 \\
\hline
\end{tabular}

\section{RESUlTS AND DisCUSSION}

\section{A. Geotechnical Properties of Expansive Soil}

The geotechnical properties of the used soil are presented in TABLE II. It was observed that the soil under consideration has $98.64 \%$ particles less than $0.075 \mathrm{~mm}$, a liquid limit of $94.51 \%$, and plastic limit of $30.55 \%$, hence a plasticity index of $63.96 \%$. According to Chen [6], soils with a plasticity index of $0-15$ has low swelling potential, those with 10-35, medium swelling potential, 20-55, high swelling potential, and greater than $35 \%$, very high swelling potential. This clearly shows that the soil under the current study is highly plastic clay soil with high swelling potential.

TABLE II. Geotechnical Properties of The Soll Under CONSIDERATION

\begin{tabular}{|l|l|l|}
\hline No. & \multicolumn{1}{|c|}{ Property } & \multicolumn{1}{c|}{ Quantity } \\
\hline 1 & Natural moisture content $\%$ & 56.68 \\
\hline 2 & Percentage passing No. 200 & 98.64 \\
\hline 3 & Liquid limit \% & 94.51 \\
\hline 4 & Plastic limit \% & 30.55 \\
\hline 5 & Plasticity index \% & 63.96 \\
\hline 6 & Specific gravity & 2.68 \\
\hline 7 & AASHTO soil classification & A-7-5 \\
\hline 8 & Free swell Index $\%$ & 130 \\
\hline 9 & Maximum dry density g/cm ${ }^{3}$ & 1.36 \\
\hline 10 & Optimum moisture content \% & 31.5 \\
\hline 11 & Unsoaked CBR at $100 \%$ MDD $(\%)$ & 11 \\
\hline 12 & Unsoaked CBR at 95\% MDD $(\%)$ & 10 \\
\hline 13 & Soaked CBR at $100 \%$ MDD $(\%)$ & 4 \\
\hline 14 & Soaked CBR at $95 \%$ MDD $(\%)$ & 3 \\
\hline 15 & UCS $\left(\mathrm{kg} / \mathrm{cm}^{2}\right)$ & 4.576 \\
\hline
\end{tabular}




\section{B. Particle Size Distribution}

The gradation for the five compositions $(0 \% \mathrm{SD}+100 \%$ Soil, 3\% SD + 97\% Soil, 5\% SD + 95\% Soil, 7\% SD + 93\% Soil, and 3\% Lime $+3 \% \mathrm{SD}+94 \%$ Soil is shown in TABLE III. It is observed that $0 \% \mathrm{SD}+100 \%$ Soil, $3 \% \mathrm{SD}+97 \%$ Soil, $5 \%$ SD $+95 \%$ Soil, and 7\% SD + 93\% Soil has 98.64\% fine aggregates (silt and clay) and $1.36 \%$ course aggregates (sand and gravel), $55.32 \%$ fine aggregates and $44.68 \%$ coarse aggregates, $70.98 \%$ fine aggregates and $29.02 \%$ coarse aggregates and, $66.28 \%$ fine aggregates and $33.72 \%$ coarse aggregates. According to AASHTO classification system, the first, second, third and fourth compositions lie under A-7-5 group, and the general rating as a subgrade material is fair to poor. The fifth composition lies under A-27 group, and the general AASHTO rating is excellent to good [19].

TABLE III. RECAPITULATION OF GRAIN-SIZE DISTRIBUTION STABILIZED SOILS

\begin{tabular}{|l|l|l|l|c|}
\hline \multirow{2}{*}{ Composition } & \multicolumn{4}{c|}{ Particle } \\
\cline { 2 - 5 } & Gravel & \multicolumn{1}{|c|}{ Sand } & Silt & Clay \\
\hline 100\%Soil+0\%SD & 0.00 & 1.36 & 45.64 & 53.00 \\
\hline 97\%Soil+3\%SD & 1.22 & 43.46 & 25.32 & 30.00 \\
\hline 95\%Soil+5\%SD & 0.00 & 29.02 & 60.98 & 10.00 \\
\hline 93\%Soil+7\%SD & 0.80 & 32.92 & 52.28 & 14.00 \\
\hline 94\%Soil+3\%Lime+3\%SD & 2.96 & 69.20 & 14.84 & 13.00 \\
\hline
\end{tabular}

\section{Free Swell Index}

The effect of sawdust on the free swell index of expansive clay soil is insignificant. The free swell index of the natural soil $(0 \% \mathrm{SD}+100 \%$ Soil $)$ is $130 \%$, and the one of the stabilized samples with $3 \% \mathrm{SD}, 5 \% \mathrm{SD}, 7 \% \mathrm{SD}$, and $3 \%$ SD $+3 \%$ lime is $110,140,130$, and $50 \%$ respectively. Soils with free swell index less than $50 \%$ are less likely to show expansion properties, while the ones with greater than $100 \%$ are susceptible to swelling under wet conditions [5]. Based on the current study, the FSI is greater than $100 \%$, thus has high chances of soil expansion during the wet season. The mixture of $3 \% \mathrm{SD}$ and $3 \%$ lime to $94 \%$ soil reduced the free swell index significantly; this really shows a reduction of expansion and swelling features.

\section{Consistency limits}

The liquid limit (LL) and plastic limit (PL) tests were carried out with different percentages of soil-sawdust mixtures. The effects of sawdust content on the liquid limit, plastic limit, and plasticity index (PI) for the sawdust- soil samples are seen in TABLE IV.

TABLE IV. THE VARIATION IN CONSISTENCY LIMIT FOR STABILIZED AND NON-STABILIZED SOILS

\begin{tabular}{|l|l|l|l|}
\hline \multicolumn{1}{|c|}{ Composition } & \multicolumn{1}{|c|}{$\begin{array}{c}\text { Liquid } \\
\text { Limit (\%) }\end{array}$} & $\begin{array}{c}\text { Plastic } \\
\text { Limit } \\
(\%)\end{array}$ & $\begin{array}{c}\text { Plasticity } \\
\text { Index } \\
(\%)\end{array}$ \\
\hline 0\%SD+100\%soil & 94.51 & 30.55 & 63.96 \\
\hline 3\%SD+97\%soil & 86.61 & 36.00 & 50.61 \\
\hline 5\%SD+95\%soil & 80.59 & 39.49 & 41.10 \\
\hline $7 \%$ SD+93\%soil & 74.98 & 38.33 & 36.65 \\
\hline 3\%SD+3\%Lime+94\%Soil & 58.78 & 42.76 & 16.01 \\
\hline
\end{tabular}

It was observed the liquid limit reduced significantly from $94.56 \%$ for the non-stabilized soil to $58.78 \%$ after replacing the soil with $3 \% \mathrm{SD}$ and $3 \%$ lime, with an increase in plastic limit from $30.55 \%$ to $42.76 \%$, thus an overall decrease in the plasticity index. The same trend was seen in the study conducted by Bell [11] in stabilizing the soils with lime. According to Burmister [7], plasticity index ranging from 1-5 is slightly plastic, 5-10 low plastic, 10-20 medium plastic, 20-40 high plasticity, and greater than 40 very high plasticity. The soil-sawdust-lime mixture sample has a plasticity index of $16.01 \%$, thus falling under medium plasticity soils. It is believed that the chemical reaction that occurred between sawdust, lime, and soil altered the size composition of the untreated soil that initially had a high liquid limit, thus reducing its plasticity index and increasing its strength and water stability [15].

\section{E. Standard Proctor's Test}

The optimum moisture content and maximum dry densities for the different compositions are presented in TABLE V. It was observed that the MDD decreases, while the OMC increases with the increase in the proportion of sawdust, and the composition of 3\% SD + 3\% Lime $+94 \%$ Soil also showed a similar trend. The decrease in the maximum dry density for the blend consisting of 3\% lime and $3 \%$ SD could be the immediate reaction of sawdust and lime with soil that is attributed by flocculation and agglomeration of the particles. On the other hand, the increase in optimum moisture content (OMC) for the sawdust-lime stabilized specimen could be the absorption of a high amount of water by lime and sawdust due to hydration [13].

TABLE V. The Optimum Moisture CONTENT AND MAXimum Dry DENSITY OF STABILIZED SAMPLES

\begin{tabular}{|l|l|l|}
\hline \multicolumn{1}{|c|}{ Composition } & $\begin{array}{c}\text { Optimum Moisture } \\
\text { Content }(\%)\end{array}$ & $\begin{array}{l}\text { Maximum Dry } \\
\text { Density (g/cm3) }\end{array}$ \\
\hline 0\%SD+100\%soil & 31.5 & 1.36 \\
\hline $3 \% \mathrm{SD}+97 \%$ soil & 32.0 & 1.259 \\
\hline $5 \% \mathrm{SD}+95 \%$ soil & 35.0 & 1.236 \\
\hline $7 \% \mathrm{SD}+93 \%$ soil & 36.0 & 1.196 \\
\hline $3 \% \mathrm{SD}+3 \%$ Lime+94\%Soil & 31.7 & 1.321 \\
\hline
\end{tabular}

\section{F. Unconfined Compressive Strength (UCS)}

The unconfined compressive strength values for soilsawdust stabilized samples are shown in Fig. 2. It was observed that the highest UCS achieved was $6.387 \mathrm{~kg} / \mathrm{cm} 2$ at $3 \%$ SD $+97 \%$ Soil, thus being the optimum percentage of sawdust needed to increase on the strength of expansive soils. The UCS for the soil-lime-sawdust mixture for different curing periods is presented in TABLE VI and Fig. 3. The UCS values of soil-lime-sawdust treated soils are higher than the Soil-Sawdust treated soils. It is observed that a combination of lime and sawdust added a significant impact on the strength of the soils, especially the 28-day cured samples. The strength is obtained from the silica and alumina that are significant components of lime. These elements react with calcium to form calcium-silicatehydrates $(\mathrm{CSH})$ and calcium-aluminate-hydrates $(\mathrm{CAH})$. $\mathrm{CSH}$ and $\mathrm{CAH}$ form the matrix that plays a vital role in the 
strength of lime treated soils. The matrix formed changes the gradation of the soil, for example; from a sandy, granular material to a hard, relatively impermeable layer with significant load-bearing capacity. The matrix formed is lifelong, durable, and significantly impermeable, producing a structural layer that is both strong and flexible [10].

TABLE VI. THE UCS VALUES FOR SAWDUST-Lime STABLiSED SAMPLES DURING DifFERENT CURING PERIODS

\begin{tabular}{|c|l|l|l|l|}
\hline Curing time (days) & 0 & 7 & 14 & 28 \\
\hline $\begin{array}{c}\text { Unconfined Compressive } \\
\text { Strength (kg/cm }\end{array}$ & 7.14 & 7.35 & 10.44 & 13.48 \\
\hline
\end{tabular}

It is seen in Fig. 3 that there was a low increase in UCS for the samples cured for 0 and 7 days while those cured for 14 and 28 days showed a tremendous increase.

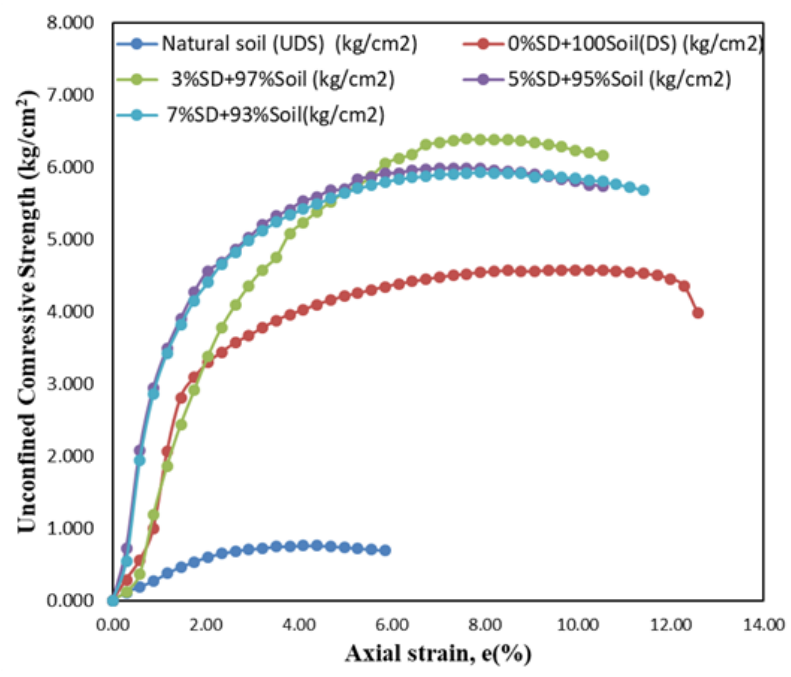

Fig. 2. UCS for different soil-sawdust mixtures.

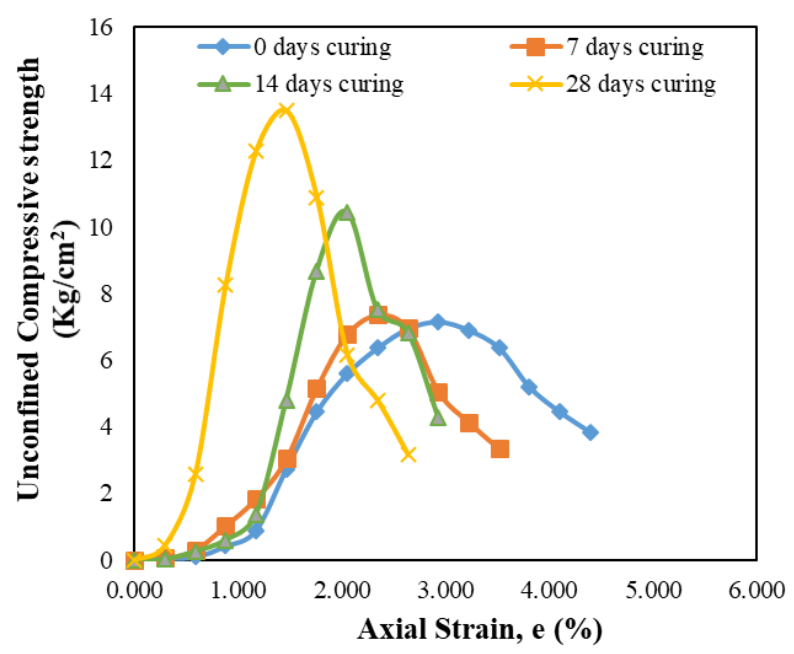

Fig. 3. UCS for 3\% SD $+3 \%$ Lime $+94 \%$ soil on different curing periods.

\section{G. California Bearing Ratio (CBR)}

The soil-sawdust-lime samples were cured for $0,7,14$, and 28 days to determine the long term bearing capacity of the soil. Substituting the soil with 3\% sawdust and 3\% lime significantly improved the CBR of the soil. The variation of unsoaked and soaked CBR values for different curing periods is presented in TABLE VII and TABLE VIII. It has been noticed that the unsoaked CBR values of sawdust-limesoil mixtures increased substantially with the increased curing periods. Strangely, some soaked CBR values for the lime-sawdust treated soils during the earlier curing periods are higher than the unsoaked values. The same scenario was reported by Amadi \& Okeiyi [13] in stabilizing lateritic soil with both quick lime and hydrated lime. The reason for the increased $\mathrm{CBR}$ for the soaked treated specimens could be the formation of cementitious chemical compounds, that are similar to the ones of portland cement such as calciumsilicate-hydrates $(\mathrm{C}-\mathrm{S}-\mathrm{H})$, calcium-aluminate-hydrates $(\mathrm{C}-$ $\mathrm{A}-\mathrm{H})$ and calcium-aluminum-silicate-hydrates $(\mathrm{C}-\mathrm{A}-\mathrm{S}-\mathrm{H})$ associated with renewed hydration of the lime and the pozzolanic reactions $[12,13]$.

TABLE VII. THE CBR VALUES FOR THE UNSOAKED SPECIMEN ( $3 \%$ SD + 3\% LIME + 94\% SOIL)

\begin{tabular}{|l|l|l|l|}
\hline \multirow{2}{*}{$\begin{array}{c}\text { Curing time } \\
\text { (days) }\end{array}$} & \multicolumn{3}{|c|}{ CBR values at different number of blows } \\
\cline { 2 - 4 } & $\mathbf{5 6}$ & $\mathbf{2 5}$ & $\mathbf{1 0}$ \\
\hline 0 & 34 & 23 & 13 \\
\hline 7 & 75 & 35 & 20 \\
\hline 14 & 78 & 40 & 17 \\
\hline 28 & 84 & 48 & 17 \\
\hline
\end{tabular}

TABLE VIII. CBR VALUES For THE SOAKED SPECIMEN $(3 \% \mathrm{SD}+3 \%$ LIME $+94 \%$ SOIL)

\begin{tabular}{|l|l|l|l|}
\hline \multirow{2}{*}{$\begin{array}{c}\text { Curing time } \\
\text { (days) }\end{array}$} & \multicolumn{3}{|c|}{ CBR values at different number of blows } \\
\cline { 2 - 4 } & $\mathbf{5 6}$ & $\mathbf{2 5}$ & $\mathbf{1 0}$ \\
\hline 0 & 37 & 32 & 13 \\
\hline 7 & 50 & 39 & 18 \\
\hline 14 & 51 & 43 & 15 \\
\hline 28 & 41 & 38 & 9 \\
\hline
\end{tabular}

\section{CONCLUSIONS}

The current study investigated the effect of curing periods on the strength of sawdust-lime stabilized expansive soil samples. Based on the analysis of the results, the following conclusions were derived;

1. The soil under study is highly plastic clay with high free swell index hence poor subgrade material.

2. The results of the UCS test revealed that lime-sawdust treated specimens experienced an increase in UCS with an increase in the curing periods with different magnitudes. At 0 , and 7 days curing, the increase was low, while at 14 , and 28 days of curing, the increase was significant.

3. The CBR values of sawdust-lime treated soils increased tremendously with the increased curing days, and the soaked CBR values for 0 day curing were higher than the unsoaked values at compaction of 56, and 25 blows, and then the same at 10 blows. For the rest of other curing days, the soaked CBR values are lower than the unsoaked values but still higher than the untreated soil sample.

Finally, it can be concluded that curing time created a significant influence on the engineering properties 
(Unconfined compressive strength and California Bearing Ratio) of the soil-sawdust-lime specimens. This was noticed by the high values of UCS and CBR obtained.

\section{ACKNOWLEDGMENT}

The authors are grateful to Diponegoro University, Soil Mechanics Laboratory, Department of Civil Engineering for availing to them all the laboratory equipment used in this research.

\section{REFERENCES}

[1] K. Al-soudany, A. Al-gharbawi, and M. Al-noori, 'Improvement of clayey soil characteristics by using activated carbon', MATEC Web Conf., vol. 01009, pp. 1-9, 2018.

[2] T. Fwa, The Handbook of Highway Engineering. United States of America: Taylor \& Francis Group, 2006.

[3] R. Parsons, 'Final Report Use of Cement Kiln Dust for Subgrade Stabilization October 2004 Kansas Department Of Transportation Division of Operations Bureau of Materials and Research', no. October, 2004

[4] V. R. Schaefer, D. J. White, H. Ceylan, and L. J. Stevens, 'Design Guide for Improved Quality of Roadway Subgrades and Subbases', Cent. Transp. Res. Educ. Iowa State Univ., no. September, 2008.

[5] K. H. Head, Manual of Soil laboratory Testing, Third edit. Scotland., UK: Whittles Publishing, 2006.

[6] F. H. Chen, Foundations on Expansive Soils, vol. 12. Amsterdam: Elsevier Scientific Publishing Company, 1975.

[7] D. M. Burmister, 'Principles and Techniques of Soil Identification', in Proceedings, Annual Highway Research Board Meeting, 1949, pp. $402-434$.

[8] W. A. Butt, B. A. Mir, and J. N. Jha, 'Strength Behavior of Clayey Soil Reinforced with Human Hair as a Natural Fibre', Geotech. Geol. Eng., vol. 34, no. 1, pp. 411-417, 2016.

[9] J. E. Edeh, I. O. Agbede, and A. Tyoyila, 'Evaluation of Sawdust Ash-Stabilized Lateritic Soil as Highway Pavement Material', $J$. Mater. Civ. Eng., vol. 26, no. 2, pp. 367-373, 2014.

[10] National Lime Association, 'Lime-Treated Soil Construction Manual Lime Stabilization \& Lime Modification', 2004.

[11] F. G. Bell, 'GEOLOGY Lime stabilization of clay minerals and soils', Eng. Geol., vol. 42, pp. 223-237, 1996.

[12] Y. J. Du, Y. Y. Zhang, and S. Y. Liu, 'Investigation of Strength and California Bearing Ratio Properties of Natural Soils Treated by Calcium Carbide Residue', Geo-Frontiers 2011, pp. 1237-1244, 2012.

[13] A. A. Amadi and A. Okeiyi, 'Use of quick and hydrated lime in stabilization of lateritic soil: comparative analysis of laboratory data', Int. J. Geo-Engineering, vol. 8, no. 1, 2017.

[14] S. Khan and H. Khan, 'Improvement of mechanical properties by waste sawdust ash addition into soil', Jordan J. Civ. Eng., vol. 10, no. 1, pp. 18-28, 2016.

[15] X. Liu, K. Sheng, J. H. Hua, B. N. Hong, and J. J. Zhu, 'Utilization of high liquid limit soil as subgrade materials with pack-andcover method in road embankment construction', Int. J. Civ. Eng., vol. 13, no. 3-4, pp. 167-174, 2015.

[16] M. Horisawa, S., Sunagawa, M., Tamai, Y., Matsuoka, Y., Tohru Miura, T., \& Terazawa, 'Biodegradation of nonlignocellulosic substances II : physical and chemical properties of sawdust before and after use as artificial soil Biodegradation of nonlignocellulosic substances I1 : physical and chemical', J. Wood Sci., vol. 45, pp. 492-49, 1999.

[17] J. Singh, N. S. Mishra, Uma, S. Banerjee, and Y. C. Sharma, 'Comparative studies of physical characteristics of raw and modified sawdust for their use as adsorbents for removal of acid dye', BioResources, vol. 6, no. 3, pp. 2732-2743, 2011.

[18] N. Phonphuak and P. Chindaprasirt, 6 - Types of waste, properties, and durability of pore-forming waste-based fired masonry bricks. Elsevier Ltd, 2015.

[19] B. M. Das, Soil Mechanics Laboratory Manual, Sixth Edit. New York: Oxford University Press, 2002.

[20] ASTM International, Standard test method for California bearing ratio (CBR) of laboratory-compacted soils. West Conshohocken, PA: ASTM D1883-14, 2014. 